\title{
Bone marrow infiltration by cells resembling plasmablasts in a patient with blastic plasmacytoid dendritic cell neoplasm
}

\author{
Alex Freire Sandes • Iracema Nunes de Castro • Thaís Elisa Miura • \\ Yumi Hasegawa Maekawa - Ana Paula Cozac • Maria de Lourdes Chauffaille • \\ Edgar Gil Rizzatti
}

Received: 7 May 2011 / Accepted: 13 May 2011 / Published online: 10 June 2011

(C) Springer-Verlag 2011

\begin{abstract}
Blastic plasmacytoid dendritic cell neoplasm (BPDCN) is a clinically aggressive hematologic malignancy derived from clonal proliferation of plasmacytoid dendritic cells. The disease has two patterns of presentation: cutaneous and leukemic. Herein we describe the case of a 9-year-old boy who presented with an unusual morphologic variant of leukemic BPDCN, showing bone marrow infiltration by medium to large cells with eccentric nuclei, regular round to oval shape, finely dispersed chromatin, one or more distinct nucleoli, and abundant basophilic cytoplasm, forming a pattern that resembled plasmablasts. Multiparameter flow cytometric immunophenotyping confirmed the diagnosis of BPDCN by identifying the expression of $\mathrm{CD} 4^{++}, \mathrm{CD} 56^{++}$, HLA-DR ${ }^{+++}$, and $\mathrm{CD} 123^{+++}$in abnormal cells, without significant expression of myeloid or lymphoid lineage-specific markers. Awareness of this plasmablastic variant of BPCDN can be helpful for directing the flow cytometry panel and the subsequent investigation of patients presenting with bone marrow infiltration by cells with plasmablastic features.
\end{abstract}

Keywords Blastic plasmacytoid dendritic cell neoplasm . Blastic NK-cell lymphoma $\cdot$ CD4+CD56+ hematodermic neoplasm · Dendritic cells $\cdot$ Morphology $\cdot$ Flow cytometry

\footnotetext{
A. F. Sandes $(\bowtie) \cdot$ T. E. Miura $\cdot$ Y. H. Maekawa • A. P. Cozac $\cdot$ M. de Lourdes Chauffaille • E. G. Rizzatti Grupo Fleury, Avenida General Valdomiro de Lima, 508, 04344-903 São Paulo, São Paulo, Brazil

e-mail: alex.sandes@fleury.com.br

I. N. de Castro

Associação Piauiense de Combate ao Câncer,

Hospital São Marcos,

Teresina, Brazil
}

\section{Case report}

Blastic plasmacytoid dendritic cell neoplasm (BPDCN) is a clinically aggressive hematologic malignancy that originates from clonal proliferation of plasmacytoid dendritic cells and their precursors [1]. BPDCN is a rare tumor, representing less than $1 \%$ of acute leukemias; it affects men 3.5 times more often than women, and most patients are adults in their fifties or older, though several cases in children have been reported [2]. The disease has two patterns of presentation: one pattern characterized by asymptomatic cutaneous lesions that are relatively indolent and tend to disseminate after variable periods $(90 \%$ of cases in adults and $75 \%$ in children) and the other pattern characterized by predominant features of acute leukemia and systemic involvement from the beginning ( $10 \%$ in adults and $25 \%$ in children) $[1,2]$. The differential diagnosis changes significantly depending on the pattern of presentation and a few patients with either cutaneous or leukemic disease may pose challenging diagnostic dilemmas. Nevertheless, unequivocal diagnosis of BPDCN is of paramount importance for patients, as this entity carries a dismal prognosis, with a median survival of only 12-14 months [1]. Recent data suggest that all patients with BPDCN, even cases with localized cutaneous lesions, must be considered to have a systemic disease par excellence, given that only aggressive regimens of treatment can improve the prognosis of patients with either localized or leukemic presentation [3]. In this regard, bone marrow transplantation seems to be the best therapy for adults [3], whereas chemotherapy protocols for high-risk acute lymphoblastic leukemia with central nervous system prophylaxis seem to be the frontline treatment of choice for children [2].

In patients with primarily cutaneous disease, the clinical history and the pattern of skin lesions often provide some important clues for diagnosis. These information, however, 
are generally unavailable - or are largely overlooked - in BPDCN cases presenting as acute leukemia. In leukemic cases, the diagnosis is frequently achieved mainly by the identification of recurrent cytomorphologic features of BPDCN cells in bone marrow or peripheral blood [4], allowing the morphologist to raise a hypothesis that can be further investigated by flow cytometric immunophenotyping when an adequate panel of monoclonal antibodies is available. Because this diagnosis requires a high index of suspicion and the recognition of sometimes subtle morphologic features, the possibility of misdiagnosis as acute leukemia or aggressive lymphoma would not be totally unanticipated. Actually, even some cases with primarily cutaneous disease may require the use of an extended panel of immunohistochemistry markers to establish the diagnosis of BPDCN. Here we present the case of a child with leukemic BPDCN-and a tumor in the leg previously diagnosed as diffuse large B-cell lymphoma - who had the bone marrow infiltrated by cells with distinctive cytomorphologic features, making a picture that looked like infiltration by plasmablasts. The study was performed according to the requirements of the institution review board.

We describe a 9-year-old boy who presented 15 days after the second cycle of CHOP chemotherapy with disseminated papules and nodules in the skin and a $10-\mathrm{cm}$ tumor in his left leg. Sixty days before presentation, the patient was attended at another hospital because of a tumor in his left leg and localized adenopathy that had appeared 10 days earlier. On that occasion, biopsy of the lesion was interpreted as diffuse large B-cell lymphoma due to weak expression of CD20 by immunohistochemistry. The tumor was reduced by $70 \%$ after the first cycle of CHOP, but increased again after the second cycle, and disseminated skin lesions developed, prompting a thorough diagnostic workup. At this point, samples of peripheral blood and bone marrow aspirate were sent to our laboratory. The complete blood count revealed the following: hemoglobin, $11.9 \mathrm{~g} / \mathrm{dL}$; mean corpuscular volume, $77.9 \mathrm{fL}$; hematocrit, $33.4 \%$; white blood cell count, $5.31 \times 10^{9} / \mathrm{L}$ ( $1 \%$ neutrophils, $7 \%$ lymphocytes, and $92 \%$ abnormal immature cells); and platelet count, $33 \times 10^{9} / \mathrm{L}$. The bone marrow aspirate was hypercellular, with $90 \%$ medium to large blasts with abundant basophilic cytoplasm (Fig. 1). The nuclei were eccentric, with regular round to oval shape, finely dispersed chromatin, one or more distinct nucleoli, and abundant basophilic cytoplasm, forming a pattern that resembled plasmablasts. Unlike immature plasma cells, however, the Golgi clear zone was located away from the nucleus in most cells (Fig. 1, arrows), and the membrane exhibited cytoplasmic projections (pseudopods) which were distinctively small and had frequent submembranous microvacuoles (Fig. 1, arrowheads). Four-color flow cytometric immunophenotyping of the bone marrow sample identified $82 \%$ abnormal cells with heterogeneous size and low internal complexity; intermediate expression of CD45; positive $\mathrm{nTdT}^{+}, \mathrm{CD}^{+}$, and $\mathrm{CD} 38^{+}$; and significant expression of $\mathrm{CD} 4^{++}, \mathrm{CD} 56^{++}, \mathrm{HLA}_{-\mathrm{DR}}^{+++}$, and $\mathrm{CD} 123^{+++}$(Fig. 2). Abnormal cells lacked CD34 and lineage-specific markers: myeloid (cMPO, CD117, CD13, CD33, and CD15), monocytic (CD11c, CD64, and CD14), lymphoid B (CD19, cCD79a, CD20, CD22, CD10, CD138, kappa, lambda, $\operatorname{IgD}, \operatorname{IgM}, \operatorname{IgA}$, and $\operatorname{IgG}$ ), and lymphoid T/NK (cCD3, sCD3, CD2, CD5, TCRalpha-beta, TCR-gamma-delta, CD16, and CD57). These results favor the diagnosis of BPDCN, as proposed by others $[4,5]$. Different from the initial immunohistochemistry staining performed elsewhere, blasts were CD20 negative by flow cytometry. Cytogenetic analysis and molecular genetic tests were not performed. The patient died only 2 days after the diagnosis of BPDCN.

This case illustrates at least two interesting points. First, we describe a morphological variant with features slightly distinct from the more common morphologic characteristics of

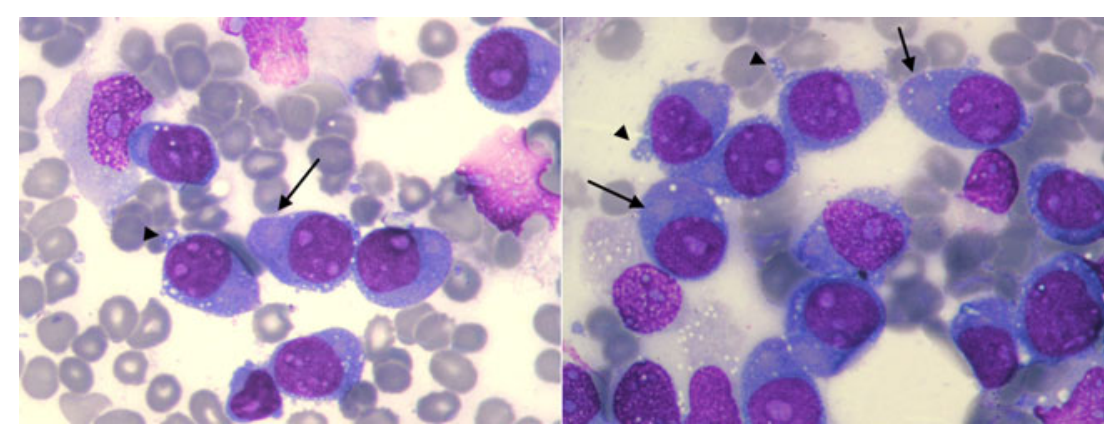

Fig. 1 Bone marrow aspirate of a 9-year-old boy with blastic plasmacytoid dendritic cell neoplasm showing medium to large blasts with abundant basophilic cytoplasm and plasmablastic features
(Leishman stain; $\times 400$ magnification). Arrows indicate the Golgi clear zone and arrowheads indicate submembranous microvacuoles inside small cytoplasmic projections (pseudopods) 



Fig. 2 Four-color flow cytometric immunophenotyping of the bone marrow sample depicted in Fig. 1 showing abnormal cells (blue) with low internal complexity (Side Scatter), heterogeneous size (Foward scatter), intermediate expression of CD45, positive CD4, CD56, HLA-DR, CD123, and CD38, and lack of cytoplasmic myeloperoxidase $(M P O)$ and $\mathrm{CD} 3$ leukemic BPDCN, frequently dominated by blasts with heterogeneous lymphomonocytoid aspects, large and overtly irregular cytoplasmic projections (pseudopods), and submembranous cytoplasmic microvacuoles that are often arranged as a pearl necklace [4]. The variant morphology illustrated by our case has significant superposition with plasmablastic transformation of multiple myeloma or B-cell lymphoma, a phenomenon that can be observed in those entities either at presentation or on disease progression. In some patients with plasmablastic infiltration of bone marrow, malignant cells show extreme pleomorphic changes, imposing a difficult differential diagnosis [6]. Although we had no problem to exclude plasmablastic myeloma or lymphoma as a diagnostic possibility in our case, as the patient was a child, this distinction can be more complicated in older adults, the population most commonly affected by BPDCN, multiple myeloma, and plasmablastic lymphoma. In such cases, a well-designed flow cytometry panel can be an invaluable tool to direct the subsequent investigation. Thus, the case presented here suggests that leukemic BPDCN should also be included as a possibility in the differential diagnosis of patients presenting with bone marrow infiltration by cells with plasmablastic features. In these situations, subtle morphologic features - namely, the localization of the Golgi clear zone relative to the nucleus and the presence of small cytoplasmic projections with submembranous microvacuoles-may serve as clues for raising the suspicion for the plasmablastic variant of BPDCN.

Second, although BPDCN was described more than 15 years ago, its cell of origin was only recently recognized [1]. Early reports of this cell type, now known as plasmacytoid dendritic cells, describe them as displaying a plasma cell-like morphology [7]. Given that we currently postulate that BPDCN is originated from clonal proliferation of immature plasmacytoid dendritic cells, perhaps BPDCN cases with plasmablastic features are the neoplastic counterpart of relatively late precursors of plasmacytoid dendritic cells, whereas the more common cases with a 
lymphomonoblastoid morphology are originated from early immature precursors.

Conflict of interest The authors declare that they have no conflict of interest.

\section{References}

1. Facchetti F (2011) Blastic plasmacytoid dendritic cell neoplasm. In: Jaffe ES, Harris NL, Vardiman JW, Campo E, Arber DA (eds) Hematopathology, 1st edn. Saunders, St. Louis, pp 788798

2. Jegalian AG, Buxbaum NP, Facchetti F, Raffeld M, Pittaluga S, Wayne AS, Jaffe ES (2010) Blastic plasmacytoid dendritic cell neoplasm in children: diagnostic features and clinical implications. Haematologica 95(11):1873-1879

3. Dalle S, Beylot-Barry M, Bagot M, Lipsker D, Machet L, Joly P, Dompmartin A, d'Incan M, Maubec E, Grange F, Dereure O, Prey S, Barete S, Wetterwald M, Fraitag S, Petrella T (2010) Blastic plasmacytoid dendritic cell neoplasm: is transplantation the treatment of choice? Br J Dermatol 162(1):74-79

4. Feuillard J, Jacob MC, Valensi F, Maynadie M, Gressin R, Chaperot L, Arnoulet C, Brignole-Baudouin F, Drénou B, Duchayne E, Falkenrodt A, Garand R, Homolle E, Husson B, Kuhlein E, Le Calvez G, Sainty D, Sotto MF, Trimoreau F, Béné MC (2002) Clinical and biologic features of CD4(+)CD56(+) malignancies. Blood 99(5):1556-1563

5. Tsagarakis NJ, Kentrou NA, Papadimitriou KA, Pagoni M, Kokkini G, Papadaki H, Pappa V, Marinakis T, Anagnostopoulos NI, Vadikolia C, Anagnostopoulos A, Angelopoulou MK, Terpos E, Poziopoulos C, Anargyrou K, Rontogianni D, Papadaki T, Psarra A, Kontopidou FN, Skoumi D, Papadhimitriou SI, Hellenic Dendritic Cell Leukemia Study Group (2010) Acute lymphoplasmacytoid dendritic cell (DC2) leukemia: results from the Hellenic Dendritic Cell Leukemia Study Group. Leuk Res 34 (4):438-446

6. Lee CK, Ma ES, Shek TW, Lam CC, Au WY, Wan TS, Chan LC (2003) Plasmablastic transformation of multiple myeloma. Hum Pathol 34(7):710-714

7. Grouard G, Rissoan MC, Filgueira L, Durand I, Banchereau J, Liu YJ (1997) The enigmatic plasmacytoid $T$ cells develop into dendritic cells with interleukin (IL)-3 and CD40-ligand. J Exp Med 185(6):1101-1111 